\title{
ASYMMETRIC VERSUS SYMMETRIC DEFECTS IN ONE-DIMENSIONAL PHOTONIC LATTICE
}

Marija T. Stojanović Krasić*

Faculty of Technology, University of Niš, Leskovac, Serbia.
(ORIGINAL SCIENTIFIC PAPER) UDC 535.317.2:535.14

Light propagation in one-dimensional photonic lattice is numerically analyzed. Two linear or nonlinear different widths asymmetric defects separated by a waveguide are located within the linear or nonlinear photonic lattice. We have found various types of localized modes located at the asymmetric defect position and at the waveguide between asymmetric defects. The results are compared with the ones obtained for light propagation in the system with the appropriate symmetric defects located within the linear or nonlinear photonic lattice.
Keywords: linear defects, nonlinear defects, photonic lattices

\section{Introduction}

Photonic lattices (PLs) are widely used for light manipulation [1, 2]. Containing weakly coupled waveguides (WGs) and enabling the modulation of refractive index, photonic lattices are a good candidate for obtaining different phenomena such as: discrete diffraction, discrete gap solitons and discrete surface waves [3-6]. Periodicity of WGs enables the existence of permitted and forbidden zones for certain frequencies [7]. The presence of defects can change the zonal structure and give the opportunity for defect modes to appear [8]. Structural symmetric and asymmetric defects, as well as nonlinear and linear defects and their affection on light propagation have been analyzed until now $[9,10]$. An asymmetric defect (AD) is considered as a WG whose dielectric function is moved from the centre of the WG towards one of the sides.

In this work, we have numerically analyzed a light beam propagating through the linear or nonlinear one-dimensional PL. Two linear or nonlinear widths different from the widths of the rest of the WGs asymmetric defects have been placed within the PL and separated by a WG. By changing the input parameters, we have found strongly localized modes at the defects position, as well as at the WG between them, whose extent of localization depends on the width and nonlinearity or linearity of the defects. Because of linearity or nonlinearity of PL and asymmetric defects as well, four combinations are studied:

- Linear asymmetric defects (ALDs) located in linear PL (LL),

- ALDs located in nonlinear PL (NL),

- Nonlinear asymmetric defects (ANDs) placed in LL,

- ANDs placed in NL.

The results received in these four combinations are compared with the results obtained for the appropriate symmetric defect (SD) in correlated PL.

The outline is organized in the following way. A math- ematical model of light propagation through the system is formulated in Section 2. Numerically obtained results are presented in Section 3. In Section 4, the conclusions have been briefly summarized.

\section{Model Equations}

Light propagation through the linear or nonlinear $\mathrm{PL}$ containing two ALDs or ANDs separated by a WG is analyzed numerically (see Figure 1a).

The light propagation through the PL with two structural ADs is modelled by the paraxial time-independent Helmholtz equation [11]:

$i \frac{\partial E}{\partial z}+\frac{1}{2 k_{0} n_{0}} \frac{\partial^{2} E}{\partial x^{2}}+k_{0} n_{0} n(x) E=0$

where $E(x, z)$ is the component of the light electric field which propagates in the $z$-direction, $k_{0}=2 \pi / \lambda$ is the wave number, $\lambda$ is the wavelength of light and $n_{0}$ is the refractive index of the substrate. Lattice is set along the $x$ - direction. Refractive index is functionally dependent on system parameters and the relation is the following:

$$
\begin{aligned}
& n_{l}(x)=\Delta n\left(\sum_{j=1}^{k-1} G_{j}\left(w_{g}, s_{A}, x\right)+G_{k}\left(w_{g k}, s_{A}, x\right)+G_{k+1}\left(w_{g}, s_{A}, x\right)+\right. \\
& \left.+G_{k+2}\left(w_{g k}, s_{A}, x\right)+\sum_{j=k+3}^{m_{A}} G_{j}\left(w_{g}, s_{A}, x\right)\right) \ldots \ldots \ldots \ldots \ldots \ldots \ldots \ldots \ldots \ldots \ldots \ldots \ldots \ldots \ldots \ldots \ldots \ldots
\end{aligned}
$$

Where $\Delta \mathrm{n}$ is the lattice potential depth, functions $G_{j}\left(w_{g}, s_{A}, x\right)$ and $G_{k}\left(w_{g} k, s_{A}, x\right)$ represent Gaussians corresponding to the WGs and ADs, respectively. The number of WGs is $m A$. Parameters $W g A$ and $W g k$ represent the width of WGs in lattices and the width of the ADs.

\footnotetext{
*Author address: Marija Stojanović Krasić, Faculty of Technology, Leskovac, University of Niš, Bulevar Oslobođenja 124, 16000 Leskovac, Serbia

E-mail: marijastojanovickrasic@yahoo.com, marijakrasic@tf.ni.ac.rs

The manuscript received: May, 24, 2018.

Paper accepted: September, 3, 2018.
} 
Parameter SA denotes the separation between WGs in the lattice. The lattice is modelled by the set of Gaussian $G_{n}(x)=\sqrt{4 \ln 2 /\left(\pi w_{g}^{2}\right)} \exp \left(-\left(\frac{x-x_{n}}{w_{g}}\right)^{2} 4 \ln 2\right)$.

The position of the centre of the nth component Gaussian is marked as $X n$. In the case of ADs centre of the Gaussian is shifted from the middle of the WG along the $x$ axis (see Figure $1 b$ and $1 c$ ). In Figure $1 b$ one can see the narrow $A D$ lattice potential compared with the narrow SD lattice potential. While in the nonlinear case, when lattice or/and $A D$ are nonlinear, refractive index consists of the linear and nonlinear part, $n(x)=n_{1}(x)+n_{n 1}(x)$

where $n_{n l}(\mathrm{x})=-(1 / 2) \mathrm{n}_{0}^{2} r E_{\mathrm{pv}} \frac{|E|^{2}}{l_{d}+|E|^{2}}$.

Parameters introduced in $\mathrm{nnl}$ represent photorefractive field Epv, the electro-optic coefficient $r$ and the dark irradiance $/ d$. In LL with the presence of AND, nonlinearity is added locally at the defect position. NL with an embedded AND implies a different value of nonlinearity at the defect position from the rest of the lattice.

In order to obtain the numerical calculation, we use dimensionless variables $\xi=k_{0} x, \eta=k_{0} z$ and $E=\sqrt{I}_{d} \Psi$. In this way, Eq. (1) obtains the following dimensionless form:

$$
i \frac{\partial \psi(\xi, \eta)}{\partial \eta}+\frac{1}{2 n_{0}} \frac{\partial^{2} \psi(\xi, \eta)}{\partial \xi^{2}}+n_{0} n(\xi) \psi(\xi, \eta=0
$$

The nonlinear term of the refraction index is in the form $n n l=\gamma|\psi(\xi, \eta)|^{2} /\left(1+|\psi(\xi, \eta)|^{2}\right)$, where $\gamma$ is a nonlinearity parameter. The nonlinearity parameter can be labelled

$$
\text { as } \Gamma=\frac{Y}{Y_{0}} \text {, where } Y_{0}=0.0001 \approx n^{3} E_{p v} r / 2 \text {. }
$$

The lattice potential depth is 0.011 [12]. The two TE polarized Gaussian light beam with FWHM $=4 \mu \mathrm{m}$ and $y=532 \mathrm{~nm}$ is used in numerical simulations. The light propagation is simulated numerically by the split-step Fourier method. The intensity of the input beam is constant, and light excites eigenmodes from the first bands in the corresponding reduced band-gap diagrams. Variable parameters in our study are the positions of ADs relative to the interface, width of ADs, nonlinearity strength of the lattices, nonlinearity strength of ANDs and transverse kick of the input beam. A transverse kick is the angle under which the light beam is inserted into the WG relatively to the $z$ axis.

\section{Results and discussion}

The model can be experimentally achieved by selective copper- or iron-doped lithium - niobat sample $20 \mathrm{~mm}$ long. In the system, WGs are $4 \mu \mathrm{m}$ wide. A distance between WGs is $4 \mu \mathrm{m}$. A FWHM of the initial Gaussian beams is $4.3 \mu \mathrm{m}$.

The changeable parameters in our study are the width of the defects and nonlinearity of the lattice and the defect as well. Two light beams are launched into the defects.
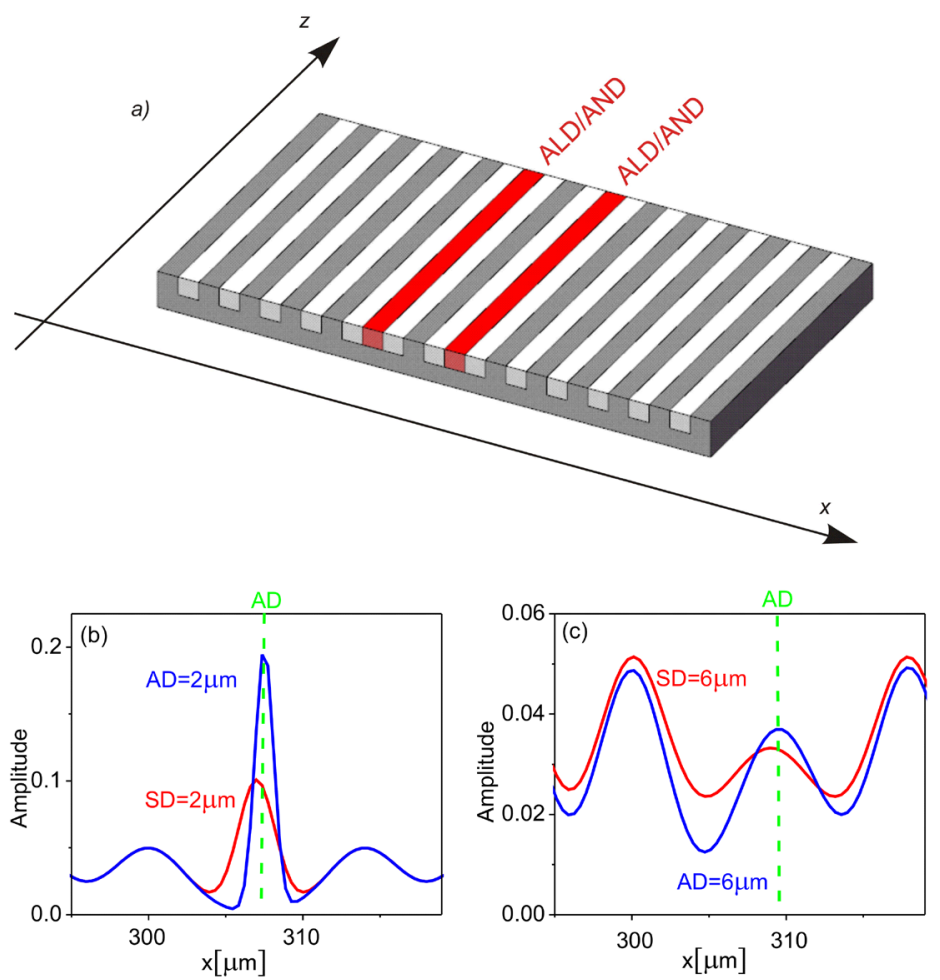

Figure 1. a) Schematic representation of the system. b) Lattice potential of $2 \mu \mathrm{m}$ wide $A D$ - narrow AD compared with the lattice potential of $2 \mu \mathrm{m}$ wide SD. c) Lattice potential of $6 \mu \mathrm{m}$ wide $A D$ - wide $A D$ in contrast with the lattice potential of $6 \mu \mathrm{m}$ wide SD. 
In order to compare the results obtained in the presence of ADs with ones obtained in the presence of SDs, we will first introduce the results obtained for light propagation in the system with SDs.

In Figure 2 one can see different types of a narrow symmetric defect $(2 \mu \mathrm{m}$ wide) in linear and nonlinear PLs. Four combinations of a symmetric defect and PL are possible. These are: symmetric linear defects (SLDs) located in LL, symmetric nonlinear defects (SNDs) placed in LL, SLDs in NL, and SND in NL. Two Gaussian beams are launched into the defect positions. Strong
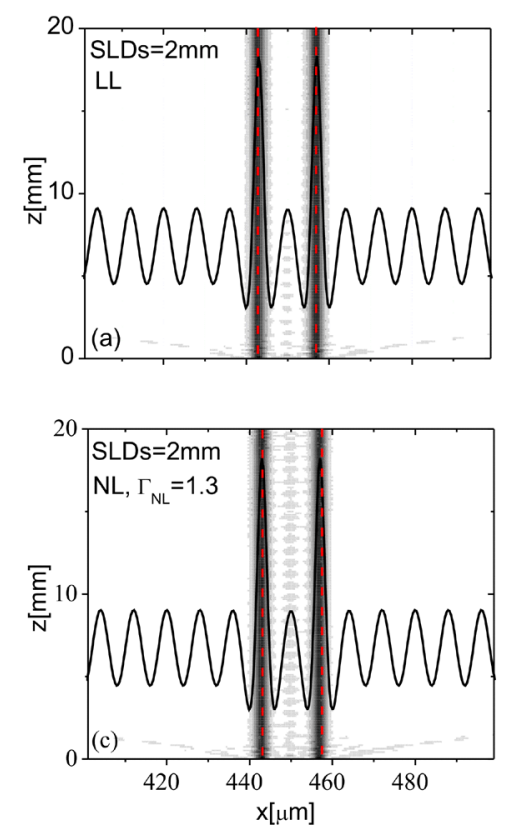

light localization is evident in all cases no matter whether the defects or lattice are linear or nonlinear. Localization is a little bit stronger in the case of SLDs located either in LL or NL (see Figure 2 a, c). Light inserted in SND cannot be immediately captured and part of energy diffracts through the lattice (see Figure $2 \mathrm{~b}, \mathrm{~d}$ ). Because of photorefractive nonlinearity of the substrate, the optimum value of nonlinearity has been used for capturing the effect. By numbers of simulations, the optimum value of nonlinearity has been obtained to be 1.3 .
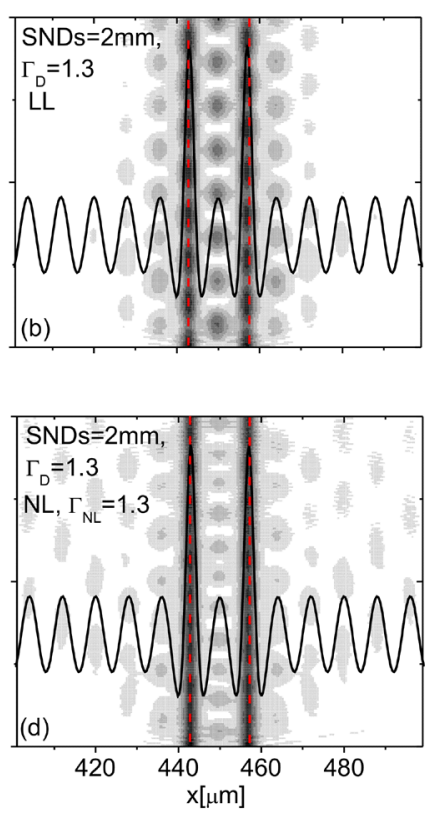

Figure 2. Two light beams inserted into the narrow symmetric defect: a) SLDs located in LL, b) SNDs with $\Gamma=1.3$ placed in LL, c) SLDs inserted in NL with $\Gamma=1.3$ and $d$ ) SNDs with $\Gamma=1.3$ located in NL with $\Gamma=1.3$.
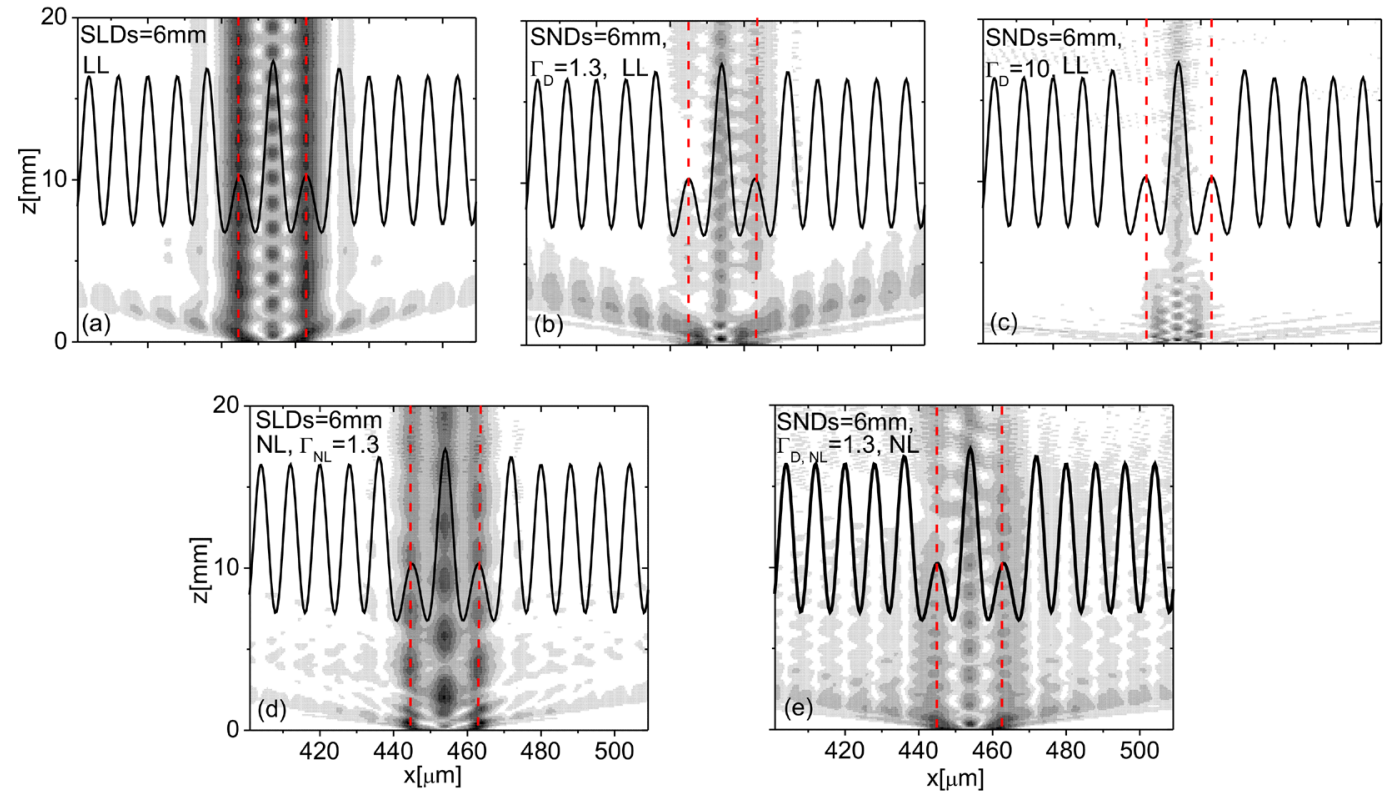

Figure 3. Two light beams inserted into the wide symmetric defect: a) SLDs located in LL, b) SNDs with $\Gamma=1.3$ placed in LL, c) SNDs with $\Gamma=10$ inserted in LL, d) SLDs located in NL with $\Gamma=1.3$ and e) SNDs with $\Gamma=1.3$ inserted in NL with $\Gamma=1.3$. 
In Figure 3 the results of wide $(6 \mu \mathrm{m})$ SLD and SND in linear and nonlinear PL are shown. A capturing effect is less effective than it is in the case of narrow SDs of any kind. It is obvious that wide SLDs located in LL gives the best capturing characteristics than any other combination of defect-lattice (see Figure 3a compared to Figure 3b-e). Nonlinearity, whether it is of the defect or of the lattice, lessens the efficiency of light capturing (see Figure $3 \mathrm{~b}-\mathrm{e}$ ).
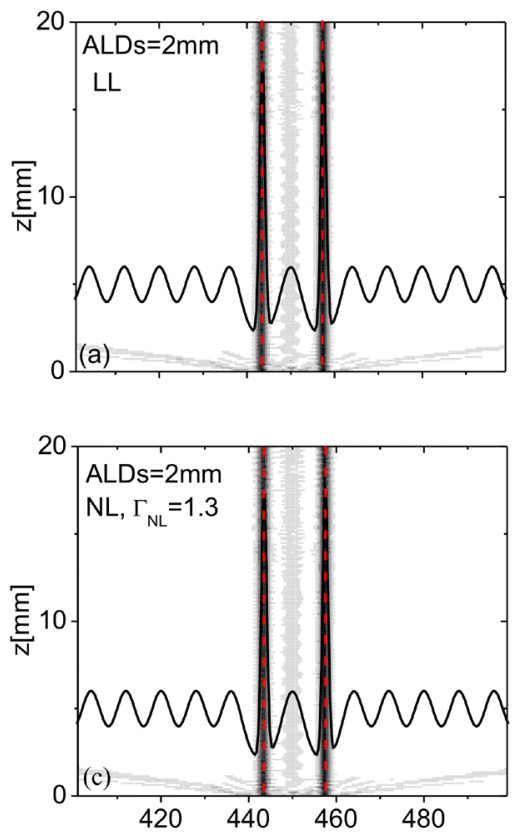

Figure 4 shows the capturing of two light beams inserted into various types of ADs. In all four combinations, $A D s-P L$, strong light localization is obtained. Even more, the localization at the ANDs is stronger than it is in SNDs. Asymmetry leads to the additional lattice potential which causes light to be trapped within the defect position.
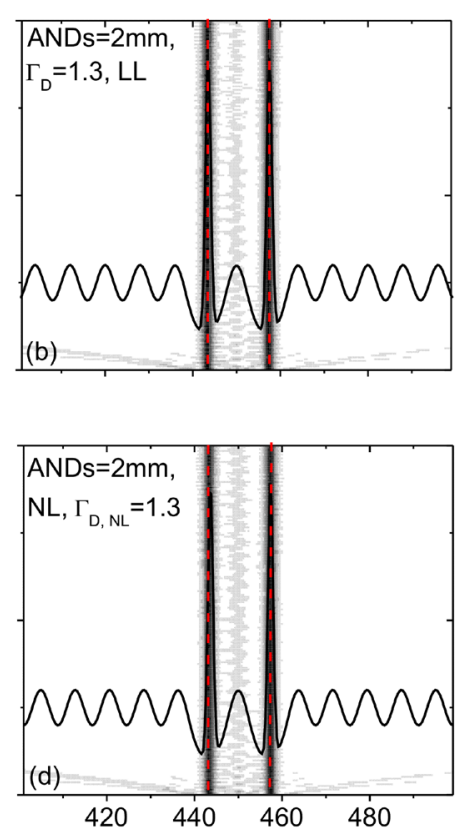

Figure 4. Two light beams inserted into the narrow asymmetric defect: a) ALDs located in LL, b) ANDs with $\Gamma=1.3$ placed in LL, c) ALDs inserted in NL with $\Gamma=1.3$ and d) ANDs with $\Gamma=1.3$ located in NL with $\Gamma=1.3$.
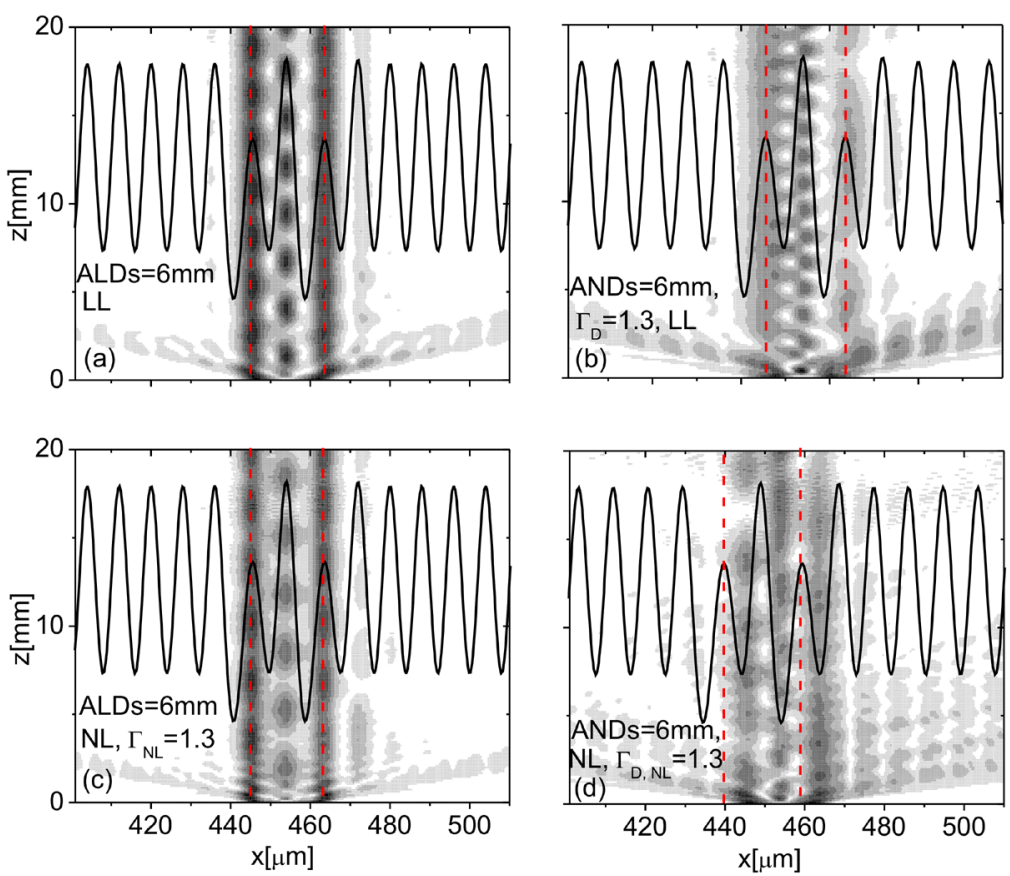

Figure 5. Two light beams inserted into the wide asymmetric defect: a) ALDs located in LL, b) ANDs with $\Gamma=1.3$ placed in LL, c) ALDs inserted in NL with $\Gamma=1.3$ and d) ANDs with $\Gamma=1.3$ located in NL with $\Gamma=1.3$. 
In Figure 5 one can see various types of wide ADs in $\mathrm{LL}$ and NL. By comparing Figure 3 and Figure 5 it can be concluded that ADs do not give any apparently different result than one obtained in the presence of SDs.

\section{Conclusion}

In this paper we have investigated the influence of asymmetric defects on light propagation through the lattice system. Lattice can be linear or nonlinear, as well as asymmetric defects. The results are compared with the ones obtained in the presence of symmetric defects. Highly localized modes are obtained in case of both, asymmetric and also symmetric defects. Asymmetry plays a significant role in the light propagation in the presence of narrow asymmetric defects, while for wide asymmetric defects the results do not differ from the results obtained for light propagation in the presence of wide SDs. The results may be useful in terms of switching, tunnelling and filtering of the light beam.

\section{References}

[1] B. S. Song, S. Noda, T. Asano, Photonic devices based on in-plane hetero photonic crystals. Science 300, (2003) 1537.

[2] R. El-Ganainy, A. Eisfeld, M. Levy, D.N Christodoulides, On-chip non-reciprocal optical devices based on quantum inspired photonic lattices. Appl. Phys. Lett. 103 (2013) 161105.

[3] H. S. Eisenberg, Y. Silberberg, R. Morandotti, J. S. Aitchison, Diffraction management. Phys. Rev. Lett. 85 (2000) 1863-1866.
[4] D. N. Christodoulides, F. Lederer, Y. Silberberg, Discretizing light behaviour in linear and nonlinear waveguide lattices. Nature 424 (2003) 817-823.

[5] A. A. Sukhorukov, Yu. S. Kivshar, H. S. Eisenberg, Y. Silberberg, Spatial optical solitons in waveguide arrays. IEEE J. Quant. Electron. 39 (2003) 31-50.

[6] S. Suntsov, K. G. Makris, D. N. Christodoulides, G. I. Stegeman, A. Haché, R. Morandotti, H. Yang, G. Salamo, M. Sorel, Observation of discrete surface solitons. Phys. Rev. Lett. 96 (2006) 063901.

[7] J. C. Knight, J. Broeng, T. A. Birks, P. St. J. Russel, Photonic Band Gap Guidance in Optical Fibers. Science 282 (1998) 1476-1478.

[8] J. D. Joannopoulos, S. G. Johnson, J. N. Winn, R. D. Meade, Photonic Crystals Molding the Flow of Light. Princeton University Press, Second edition (2008).

[9] T. J. Alexander, A. A. Sukhorukov, Yu. S. Kivshar, Asymmetric vortex solitons in nonlinear periodic lattices. Phys. Rev. Lett. 93 (2004) 063901.

[10] Y. V. Kartashov, V. V. Vysloukh, L. Torner, Highly asymmetric soliton complexes in parabolic optical lattices. Opt. Lett. 33 (2008) 141-143.

[11] S. Kuzmanović, M. Stojanović Krasić, D. Milović, M. Miletić, A. Radosavljević, G. Gligorić, A. Maluckov, M. Stepić, Light propagation inside 'cavity' formed between nonlinear defect and interface of two dissimilar onedimensional linear photonic lattices. Eur. Phys. J. D 69, (2015) 207

[12] A. Kanshu, C. E. Rüter, D. Kip, V. M. Shandarov, Opticallyinduced defect states in photonic lattices: formation of defect channels, directional couplers, and disordered lattices leading to Anderson-like light localization. Appl. Phys. B 95, (2009) 537-543.

Izvod

\section{ASIMETRIČNI NASUPROT SIMETRIČNIM DEFEKTIMA U JEDNO-DIMENZIONALNOJ FOTONSKOJ REŠETKI}

Marija T. Stojanović Krasić

Tehnološki fakultet, Univerzitet u Nišu, Leskovac, Srbija

Prostiranje svetlosti u jedno-dimenzionalnoj fotonskoj rešetki je numerički proučavano. Dva linearna ili nelinearna asimetrična defekta različitih širina razdvojena jednim talasovodom locirani su unutar linearne ili nelinearne fotonske resetke. Pronađene su različite vrste lokalizovanih moda koje se nalaze na pozicijama asimetričnih defekata kao i u talasovodu između asimetričnih defekata. Rezultati su upoređeni sa rezultatima dobijenim za slučaj propagacije svetlosti u sistemu sa odgovarajućim simetričnim defektima lociranim u linernoj ili nelinearnoj fotonskoj rešetki.
(ORIGINALNI NAUČNI RAD) UDK 535.317.2:535.14
Ključne reči: linearni defekti, nelinearni defekti, fotonske rešetke 